\title{
COMMUNICATION
}

Cite this: DOI: $10.1039 /$ xoxxooooox

\section{Alignment of Nanostructured Tripeptide Gels by Directional Ultrasonication ${ }^{\dagger}$}

\author{
Charalampos G. Pappas, ${ }^{\mathrm{a}, \mathrm{b}}$ Pim W. J. M. Frederix, ${ }^{\mathrm{b}}$ Tapiwa Mutasa, ${ }^{\mathrm{c}}$ Scott Fleming, ${ }^{\mathrm{b}}$ \\ Yousef M. Abul-Haija, ${ }^{\mathrm{b}}$ Sharon M. Kelly, ${ }^{\mathrm{d}}$ Anthony Gachagan, ${ }^{\mathrm{c}}$ Daniela Kalafatovic, ${ }^{\mathrm{a}}$ \\ Jacob Trevino, ${ }^{a}$ Rein V. Ulijn* ${ }^{\mathrm{a}, \mathrm{b}}$ and Shuo Bai*a,b
}

Received ooth January 2012, Accepted ooth January 2012

DOI: 10.1039/xoxx00000x

www.rsc.org/

We demonstrate an in-situ ultrasonic approach to influence self-assembly across the supramolecular to micron length scales, showing enhancement of supramolecular interactions, chirality and orientation, which depends on the peptide sequence and solvent environment. This is the first successful demonstration of using oscillating pressure waves to generate anisotropic organo- and hydro- gels consisting of oriented tripeptides structures.

Peptides are versatile building blocks for the formation of structured materials for a range of applications in biomedicine and bionanotechnology. ${ }^{1}$ However, while they may be highly organized at the supramolecular (nanoscale) level, most self-assembling materials are disordered at the macro-scale. The ability to control their orientation across the length scales opens up ways to better control mechanical, optical and electronic properties. ${ }^{2}$

A number of approaches have been used to align both inorganic and organic materials. These include Langmuir-Blodgett techniques, lithography, chemical vapor deposition, magnetic and electric fields. ${ }^{3}$ Several successful examples have been reported to generate anisotropic gels but few methods allow for in-situ alignment in solution or the gel-phase. Stupp's group demonstrated a thermal pathway to process self-assembling peptide amphiphiles into highly aligned macrostructures. ${ }^{4 a}$ Yan and co-workers used heating to trigger covalent crosslinking of cyclo-dipeptides leading to highly ordered peptide crystals. ${ }^{4 \mathrm{~b}, 4 \mathrm{c}} \mathrm{Xu}$ and co-workers reported an enzymatic self-assembly approach which, by nature of the aromatic side chains of peptides used, resulted in alignment of fibers through aromatic-aromatic interactions for generating anisotropic hydrogels. ${ }^{4 \mathrm{~d}}$ Furthermore, the shear-flow and magnetic field were also used to align macroscopic domains within peptide hydrogels. ${ }^{4 \mathrm{e}-\mathrm{f}}$

Ultrasound, i.e. high frequency $(>20 \mathrm{kHz})$ pressure waves, is commonly used in supramolecular chemistry to overcome energy barriers and disrupt intermolecular interactions, which has been used routinely to control self-assembly and gelation processes, ${ }^{5}$ including most recently the demonstration of dynamic and transient reconfiguration of peptide nanostructures. ${ }^{5 \mathrm{~g}}$ We reasoned that the directionality of sound waves - longitudinal pressure waves which lead to oscillating compression of the solvent volume in the same direction as the wave itself- may provide opportunities to introduce anisotropy in gel-phase, especially if the ultrasound is applied directionally. Thus, in this work we demonstrate the use of ultrasound to trigger the self-assembly and alignment of tripeptide nanostructures resulting in thermodynamically stable anisotropic organo- and hydrogels (Scheme 1).
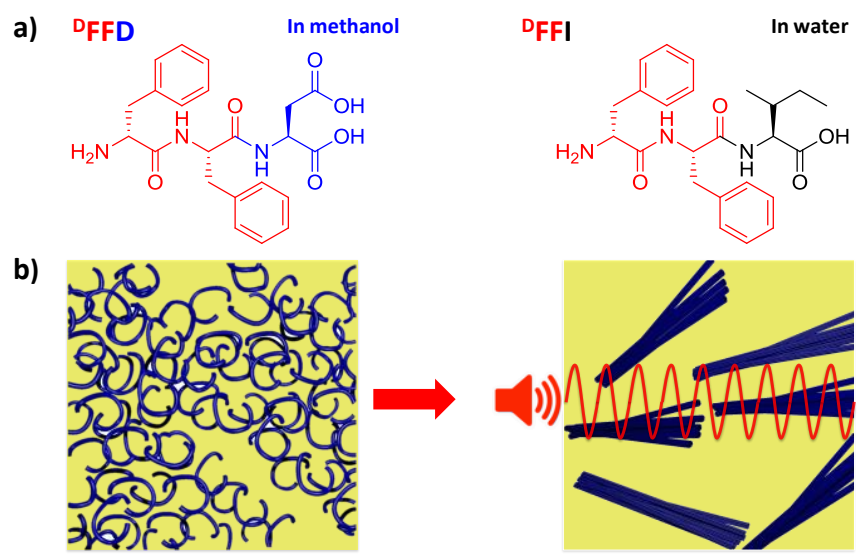

Scheme 1 (a) Chemical structures of tri-peptide derivatives of ${ }^{\mathrm{D}} \mathrm{FFI}$ and ${ }^{\mathrm{D}}$ FFD. (b) Cartoon of self-assembly of ${ }^{\mathrm{D}}$ FFD and ${ }^{\mathrm{D}} \mathrm{FFI}$ altering from disordered short fibers to highly oriented fibrous clusters after ultrasound exposure in methanol ( $\left.{ }^{\mathrm{D} F F D}\right)$ and buffer solution ( $\left.\mathrm{pH} 8,{ }^{\mathrm{D}} \mathrm{FFI}\right)$.

The D-L-L stereochemistry in tripeptides was previously shown to give rise to self-supporting hydrogels by Hartley's group ${ }^{6}$ without the need for modification with aromatic $^{1 \mathrm{a}}$ or aliphatic ${ }^{1 \mathrm{~b}}$ groups normally required for short peptide gelation. Here, we use tripeptides 
${ }^{\mathrm{D}}$ FFD $\left({ }^{\mathrm{D}}\right.$-phenylalanine- ${ }^{\mathrm{L}}$-phenylalanine- ${ }^{\mathrm{L}}$-aspartic acid $)$ and ${ }^{\mathrm{D}} \mathrm{FFI}\left({ }^{\mathrm{D}}\right.$ phenylalanine- ${ }^{\mathrm{L}}$-phenylalanine- ${ }^{\mathrm{L}}$-isoleucine), which could form gelphase materials in methanol and aqueous solution triggered by ultrasonic effect, respectively. Tripeptides were synthesized by using the standard Fmoc (Fluorenylmethyloxycarbonyl)- $t$ Bu strategy (for details on synthesis, see Experimental Section). $10 \mathrm{mg}$ of ${ }^{\mathrm{D}}$ FFD was fully dissolved in $1 \mathrm{ml}$ methanol $(25 \mathrm{mM})$ by heating up to $50{ }^{\circ} \mathrm{C}$. After cooling down to room temperature, a precipitate was observed (Figure 1a). The solubility of ${ }^{\mathrm{D}}$ FFD in methanol determined by UVVis spectroscopy is $20 \mathrm{mM}$. Transmission electron microscopy (TEM) images show that the precipitate consists of random, short and curved nanofibres (Figure 1a). For the ultrasonic experiments, we used a purpose-built setup, consisting of a glass beaker with a piezo-transducer $(80 \mathrm{kHz})$ attached to the bottom, which could provide one-directional ultrasonic pressure with constant amplitude, rather than general sonication bath with varied frequencies and directions (for details on ultrasonic setup, see Experimental Section). Upon ultrasound exposure during cooling of the peptide solution for 60 seconds, a gel-phase material may be observed (Figure 1b). Scanning and transmission electron microscopy (SEM and TEM) showed formation of aligned peptide structures consisting of tubelike nanostructures of approximately $15 \mathrm{~nm}$ in diameter that, in turn, organize into bundles of microtubes (approximately $1 \mu \mathrm{m}$ in diameter) of tens of $\mu \mathrm{m}$ in length (Figure 1c and 1d). Two-photon microscopy of structures labelled with thioflavin T (ThT) (dissolved with ${ }^{\mathrm{D}}$ FFD in methanol) ${ }^{1 \mathrm{f}}$ further supported formation of microstructures in the gel-phase, verifying that structures observed by electron microscopy were not drying induced artefacts during sample preparation (Figure 1e). a)

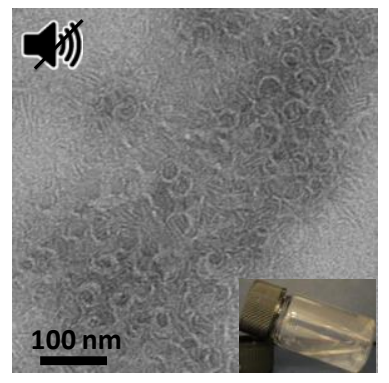

b)

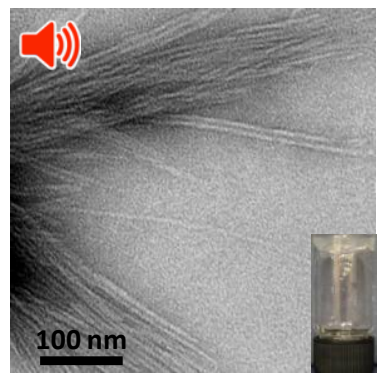

c)

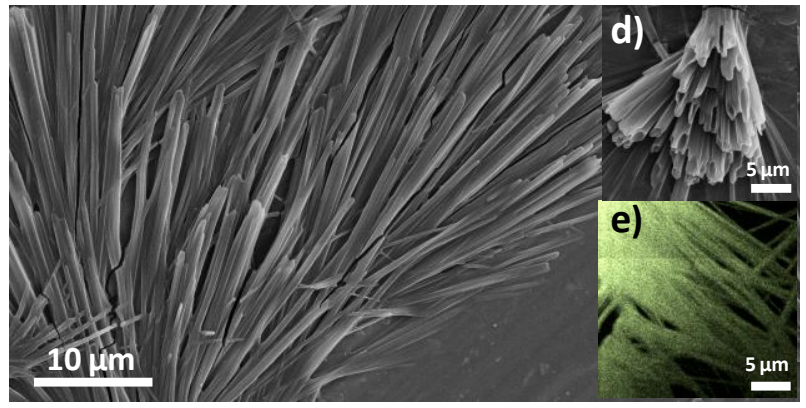

Fig. 1 TEM images of ${ }^{D}$ FFD in methanol (a) before and (b) after ultrasound exposure. Inset photographs are ${ }^{\mathrm{D}} \mathrm{FFD}$ forming precipitation or gel without or with ultrasound in methanol. (c, d) SEM and (e) Two-photon microscopy images of the ultrasonicated ${ }^{\mathrm{D}} \mathrm{FFD}$ peptide gels. The scale bars are (a) $100 \mathrm{~nm}$, (b) $100 \mathrm{~nm}$, (c) $10 \mu \mathrm{m}$, (d) $5 \mu \mathrm{m}$ and (e) $5 \mu \mathrm{m}$. The concentration is $25 \mathrm{mM}$.

We used nuclear magnetic resonance (NMR) Spectroscopy to obtain insights into the supramolecular transitions induced by ultrasound. As Figure S1 shows, after exposure of ${ }^{\mathrm{D}} \mathrm{FFD}$ to ultrasound, a downfield shift was observed suggesting change in the chemical environment with enhanced supramolecular interactions.
We further investigated these observations using diffusion-ordered spectroscopy (DOSY). These experiments reveal that the diffusion becomes slower upon application of ultrasound, suggesting supramolecular reorganization towards formation of larger structures (Figure S1).

To gain insights into the chiral organization of the peptide structures, the presence of chirally organized phenyl moieties and orientation of self-assembled structures within the tripeptide before and after ultrasound, circular (CD) and linear dichroism (LD) spectroscopy were used. As Figure 2a shows, a CD and LD silent spectrum can be obtained for ${ }^{\mathrm{D}}$ FFD before ultrasound. Remarkably, sound waves induced supramolecular chirality by significantly enhancing the peaks at 240 and $270 \mathrm{~nm}$ in the organogel, which may be attributed to the supramolecular organization of chiral centers within $\pi-\pi$ stacking of phenylalanines. ${ }^{6 a, 7} \mathrm{LD}$ spectra show that a minimum at $205 \mathrm{~nm}$ and a maximum at $255 \mathrm{~nm}$ are observed which indicates both perpendicular and parallel orientation of phenyl moieties to the axis exist in self-assembled structures (Figure $\mathbf{2 b}$ ). ${ }^{8}$
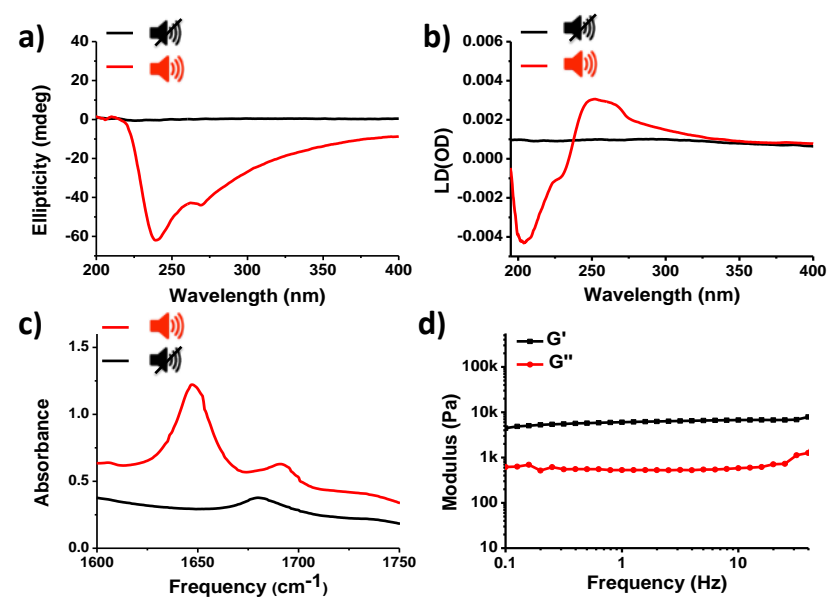

Fig. 2 (a) CD, (b) LD and (c) FT-IR spectra of ${ }^{\mathrm{D}}$ FFD in methanol before and after ultrasound irradiation. (d) Rheology of the elastic modulus $\left(G^{\prime}\right)$ and viscous modulus $\left(\mathrm{G}^{\prime \prime}\right)$ of ${ }^{\mathrm{D}} \mathrm{FFD}$ organogel after ultrasound irradiation. The concentration is $25 \mathrm{mM}$.

Infrared spectroscopy in the amide I region of the spectrum (1600$1700 \mathrm{~cm}^{-1}$ ) was used to determine the hydrogen bonding networks within the fibrous structures. Spectra of the samples with and without ultrasound treatment are displayed in Figure 2c. The suspended precipitate of ${ }^{\mathrm{D}}$ FFD exhibits a weak, broad peak around $1680 \mathrm{~cm}^{-1}$, suggesting the presence of unstructured or solvated amide groups. Notably, a strong redshift of the amide absorption around $1650 \mathrm{~cm}^{-1}$ was observed upon ultrasound exposure, together with a second peak around $1694 \mathrm{~cm}^{-1}$. These observations suggest a more ordered H-bonding pattern. ${ }^{1 \mathrm{a},} 9$ Figure 2d shows the linear viscoelastic responses of the ${ }^{\mathrm{D}} \mathrm{FFD}$ organogels. The storage modulus $\left(G^{\prime}\right)$ exceeds the loss modulus $\left(G^{\prime \prime}\right)$ by factor of 12 demonstrating that the tripeptides formed viscoelastic gels. Overall, these results revealed that the size transition of peptide self-assembled structures from nano- to micron scale was acoustically induced, where supramolecular chirality and orientation of peptide microtubes and hydrogen bonding interactions were dramatically enhanced (Scheme 1).

In water, gelation was not observed for ${ }^{\mathrm{D}} \mathrm{FFD}$, most likely due to the hydrophilicity of charged aspartic acid. The peptide sequence was therefore adapted to increase the hydrophobicity. By changing aspartic acid ( $\left.{ }^{\mathrm{D}} \mathrm{FFD}\right)$ to more hydrophobic isoleucine ( ${ }^{\mathrm{D} F F I}$ ), the ultrasonic alignment can be used to fabricate anisotropic hydrogels, indicating that the anisotropic arrangement of supramolecular 
interactions is highly related to the peptide sequences and solvent environment. $12.5 \mathrm{mg}$ of ${ }^{\mathrm{D}} \mathrm{FFI}$ was dissolved in $1 \mathrm{ml}$ phosphate buffer solution $(\mathrm{pH} 8)(30 \mathrm{mM})$. The solubility was enhanced by heating up to $80{ }^{\circ} \mathrm{C}$. After cooling down to room temperature, a precipitate consisting of entangled short nanofibers was observed (Figure 3a). The solubility of ${ }^{\mathrm{D}}$ FFI in buffer solution determined by UV-Vis spectroscopy is $15.5 \mathrm{mM}$. When in-situ ultrasound treatment was introduced to the ${ }^{\mathrm{D}}$ FFI buffer solution for 30 seconds during the cooling process, a hydrogel was obtained. TEM images show that the self-assembled peptide structure changes to bundles of highly oriented microfibers (Figure 3b). SEM images indicate that the macroscopic alignment of peptide fibers up to $1 \mu \mathrm{m}$ of thickness and $100 \mu \mathrm{m}$ of length are achieved (Figure 3c). Two-photon microscopy image showed the formation of micro-structure of ${ }^{\mathrm{D}} \mathrm{FFI}$ in the gelphase (Figure 3d).

a)
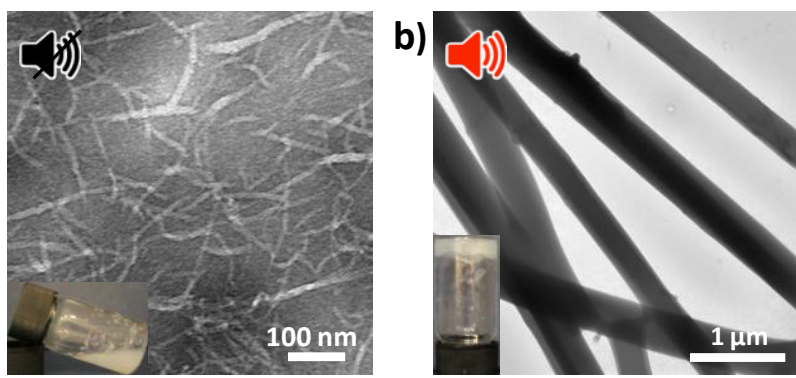

c)

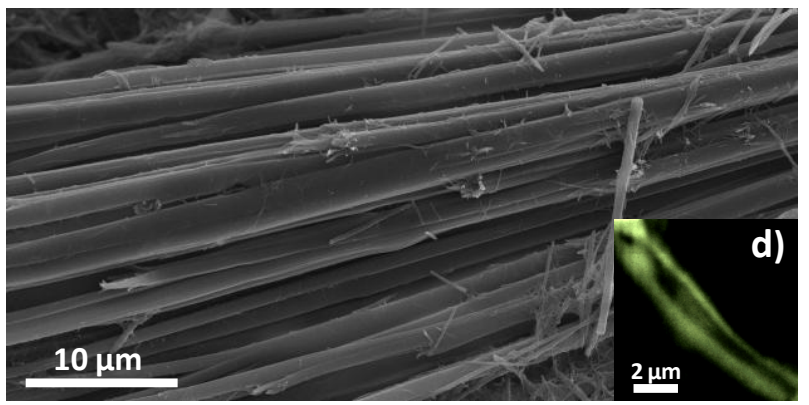

Fig. 3 TEM images of ${ }^{D}$ FFI in phosphate buffer ( $\mathrm{pH}$ 8) (a) before and (b) after ultrasound irradiation. Inset photographs are ${ }^{\mathrm{D}} \mathrm{FFI}$ forming solution or gel without or with ultrasound in buffer. (c) SEM image and (d) Two-photon microscopy images of the ultrasonicated ${ }^{\mathrm{D}}$ FFI peptide gels. The scale bars are (a) $100 \mathrm{~nm}$, (b) $1 \mu \mathrm{m}$, (c) $10 \mu \mathrm{m}$ and (d) $2 \mu \mathrm{m}$. The concentration is $30 \mathrm{mM}$.

To acquire more insights at the supramolecular level in the aqueous media, the samples were characterized by spectroscopic methods. Significant enhancement of CD and LD signal at $215 \mathrm{~nm}$ revealed the presence of chiral centers within $\beta$-sheet type arrangement and perpendicular orientation of phenyl moieties to the axis in self-assembled structures after ultrasonic exposure (Figure 4a, b). IR absorption spectra were taken by using deuterated phosphate buffer at pD 8 and show a broad band from 1635 to 1650 $\mathrm{cm}^{-1}$ (Figure 4c), indicating a less ordered H-bonding pattern between the peptide backbones. ${ }^{9}$ Figure 4d shows the linear viscoelastic responses of the ${ }^{\mathrm{D}}$ FFI hydrogels. The storage modulus $\left(G^{\prime}\right)$ exceeds the loss modulus $\left(G^{\prime \prime}\right)$ by factor of 22 demonstrating that the tripeptides formed viscoelastic gels. The results indicate that using one-directional ultrasound, which provides differential influences of self-assembly of peptides in both organic and aqueous media by dramatically increasing the hydrophobic stacking and hydrophilic hydrogen bonding interactions, gives rise to the enhancement of chirality, orientation and gelation process.

Following the same experimental procedure as mentioned above, we used a standard sonication bath (The frequency is around $40 \mathrm{KHz}$ with varied acoustic pressure and amplitude.) as a control experiment. Figure S2 shows that the sonication bath can also trigger the gelation of ${ }^{\mathrm{D}}$ FFD in methanol and ${ }^{\mathrm{D}}$ FFI in buffer solution. However, disordered fibrous structures are observed by SEM (Figure S2), which proves that oscillating pressure waves give rise to the highly oriented peptide self-assembly.
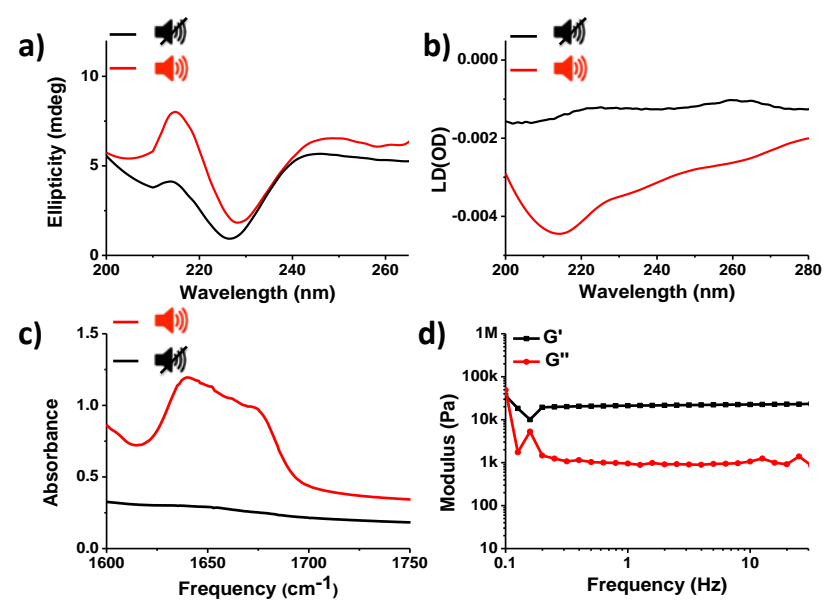

Fig. 4 (a) CD (Circular Dichroism), (b) LD (Linear Dichroism) and (c) FT-IR spectra of ${ }^{\mathrm{D}} \mathrm{FFI}$ in phosphate buffer $(\mathrm{pH}$ 8) before and after ultrasound irradiation. (d) Rheology of the elastic modulus $\left(\mathrm{G}^{\prime}\right)$ and viscous modulus $\left(G^{\prime \prime}\right)$ of ${ }^{D}$ FFI hydrogel after ultrasound irradiation. The concentration is 30 $\mathrm{mM}$.

\section{Conclusions}

In conclusion, we demonstrate the use of ultrasonic waves as an in-situ approach to induce the self-assembly and alignment of tripeptides forming highly ordered micro- fibrous structures in both organic and aqueous media. Two different peptides were studied, ${ }^{D}$ FFD and ${ }^{D}$ FFI with the former forming an anisotropic organogel in methanol, while the latter forms an anisotropic hydrogel, showing that the anisotropic arrangement of supramolecular interactions is highly related to the peptide sequences and solvent environment. These results indicate that the influence of ultrasound transcends the molecular to nanoand micron length scales. The ultrasonic approach may give rise to facilitate amelioration of organization and mechanical properties supramolecular nanostructures.

\section{Acknowledgements}

We thank Dr. Margaret Mullin for SEM and TEM measurement, Prof. Gail McConnell for help with two-photon microscopy measurement and Craig Irving for the DOSY experiments. The research leading to these results has received funding from the European Research Council under the European Union's Seventh Framework Programme (FP7/20072013) / EMERgE/ ERC grant agreement $n^{\circ}$ [258775]. CGP would like to thank Linn Products Ltd for funding. Y.M.A. acknowledges financial support by FP7 Marie Curie Actions of the European Commission, via the initial training network ReAd (no. 289723).

\section{Notes and references}


${ }^{a}$ Advanced Science Research Center (ASRC) and Hunter College, City University of New York, New York, NY10031, USA. E-mail: Rein.Ulijn@asrc.cuny.edu.

b WestCHEM, Department of Pure \& Applied Chemistry, Thomas Graham Building, 295 Cathedral Street, University of Strathclyde, G1 1XL Glasgow, UK. E-mail: shuo.bai@strath.ac.uk.

c Centre for Ultrasonic Engineering, Department of Electronic \& Electrical Engineering, University of Strathclyde, 204 George Street, Glasgow G1 1XW, U.K.

${ }^{\mathrm{d}}$ Institute of Molecular, Cell and Systems Biology College of Medical, Veterinary and Life Sciences, University of Glasgow G128QQ, U.K.

$\dagger$ Electronic Supplementary Information (ESI) available: Materials, characterization for new compounds, DOSY, experimental details and the setup of equipment. See DOI: 10.1039/c000000x/

1. (a) S. Fleming, R. V. Ulijn, Chem. Soc. Rev., 2014, 43, 8150-8177; (b) T. Aida, E. W. Meijer, S. I. Stupp, Science, 2012, 335, 813-817; (c) A. L. Boyle, D. N. Woolfson, Chem. Soc. Rev., 2011, 40, 4295-4306; (d) I. W. Hamley, Angew. Chem. Int. Ed., 2014, 53, 6866-6881; (e) P. W. J. M. Frederix, G. G. Scott, Y. M. Abul-Haija, D. Kalafatovic, C. G. Pappas, N. Javid, N. T. Hunt, R. V. Ulijn, T. Tuttle, Nat. Chem., 2015, 7, 30-37; (f) S. Bai, C. G. Pappas, S. Debnath, P. W. J. M. Frederix, J. Leckie, S. Fleming, R. V. Ulijn, ACS Nano, 2014, 8, 7005-7013; (g) Y. Kuang, J. F. Shi, J. Li, D. Yuan, K. A. Alberti, Q. B. Xu, B. Xu, Angew. Chem. Int. Ed., 2014, 53, 8104-8107.

2. (a) A. W. Feinberg, A. Feigel, S. S. Shevkoplyas, S. Sheehy, G. M. Whitesides, K. K. Parker, Science, 2007, 317, 1366-1370; (b) A. Merzlyak, S. Indrakanti, S. W. Lee, Nano Lett., 2009, 9, 846-852; (c) C. J. Bettinger, R. Langer, J. T. Borenstein, Angew. Chem. Int. Ed., 2009, 48, 5406-5415; (d) R. Nelson, M. R. Sawaya, M. Balbirnie, A. Ø. Madsen, C. Riekel, R. Grothe, D. Eisenberg, Nature, 2005, 435, 773-778; (e) C. M. Dobson, Nature, 2003, 426, 884-890.

3. (a) S. W. Choi, W. S. Kang, J. H. Lee, C. K. Najeeb, H. S. Chun, J. H. Kim, Langmuir, 2010, 26, 15680-15685; (b) B. H. Kim, D. O. Shin, S. J. Jeong, C. M. Koo, S. C. Jeon, W. J. Hwang, S. Lee, M. G. Lee, S. O. Kim, Adv. Mater., 2008, 20, 2303-2307; (c) D. Kohler, M. Schneider, M. Kruger, C. M. Lehr, H. Moehwald, D. Y. Wang, $A d v$. Mater., 2011, 23, 1376-1379; (d) M. Reches, E. Gazit, Nature Nanotech., 2006, 1, 195-200; (e) M. C. Vasudev, H. Koerner, K. M. Singh, B. P. Partlow, D. L. Kaplan, E. Gazit, T. J. Bunning, R. R. Naik, Biomacromolecules, 2014, 15, 533-540; (f) B. R. Cao, Y. Zhu, L. Wang, C. B. Mao, Angew. Chem. Int. Ed., 2013, 53, 11750-11754; (g) R. J. A. Hill, V. L. Sedman, S. Allen, P. M. Williams, M. Paoli, L. Adler-Abramovich, E. Gazit, L. Eaves, S. J. B. Tendler, Adv. Mater. 2007, 19, 4474-4479.

4. (a) S. M. Zhang, M. A. Greenfield, A. Mata, L. C. Palmer, R. Bitton, J. R. Mantei, C. Aparicio, M. O. de la Cruz, S. I. Stupp, Nat. Mater., 2010, 9, 594-601; (b) X. H. Yan, J. B. Li, H. Möhwald, Adv. Mater., 2011, 23, 2796-2801; (c) X. Yan, Y. Su, J. Li, J. Früh, H. Möhwald, Angew. Chem. Int. Ed., 2011, 50, 11186-11191; (d) J. Zhou, X. Du, Y. Gao, J. Shi, B. Xu, J. Am. Chem. Soc., 2014, 136, 2970-2973; (e) B. D. Wall, S. R. Diegelmann, S. Zhang, T. J. Dawidczyk, W. L. Wilson, H. E. Katz, H. Q. Mao and J. D. Tovar, Adv. Mater., 2011, 23, 50095014; (f) M. Wallace, A. Z. Cardoso, W. J. Frith, J. A. Iggo, D. J. Adams, Chem. Eur. J., 2014, 20, 16484-16487.
5. (a) Y. B. Wang, C. L. Zhan, H. B. Fu, X. Li, X. H. Sheng, Y. S. Zhao, D. B. Xiao, Y. Ma, J. S. Ma, J. N. Yao, Langmuir, 2008, 24, 76357638; (b) A. M. Hung, S. I. Stupp, Langmuir, 2009, 25, 7084-7089; (c) N. Komiya, T. Muraoka, M. Iida, M. Miyanaga, K. Takahashi, T. Naota, J. Am. Chem. Soc. 2011, 133, 16054-16061; (d) L. Sambri, F. Cucinotta, G. De Paoli, S. Stagni, L. De Cola, New J. Chem., 2010, 34, 2093-2096; (e) A. Kotal, T. K. Paira, S. Banerjee, T. K. Mandal, Langmuir, 2010, 26, 6576-6582; (f) G. Cravotto, E. C. Gaudino, P. Cintas, Chem. Soc. Rev., 2013, 42, 7521-7534; (g) C. G. Pappas, T. Mutasa, P. W. J. M. Frederix, S. Fleming, S. Bai, S. Debnath, S. M. Kelly, A. Gachagan, Rein V. Ulijn, Mater. Horiz., 2015, 2, 198-202; (h) D. Ke, C. Zhan, X. Li, X. Wang, Y. Zeng, J. Yao, J. Colloid Interface Sci., 2009, 337, 54-60.

6. (a) S. Marchesan, C. D. Easton, F. Kushkaki, L. Waddington, P. G. Hartley, Chem. Commun., 2012, 48, 2195-2197; (b) S. Marchesan, C. D. Easton, K. E. Styan, L. Waddington, F. Kushkaki, L. Goodall, K. M. McLean, J. S. Forsythe, P. G. Hartley, Nanoscale, 2014, 6, 51725180 .

7. S. Marchesan, L. Waddington, C. D. Easton, D. A. Winkler, L. Goodall, J. S. Forsythe, P. G. Hartley, Nanoscale, 2012, 4, 67526760 .

8. (a) R. Adachi, K. Yamaguchi, H. Yagi, K. Sakurai, H. Naiki, Y. Goto, J. Bio. Chem., 2007, 282, 8978-8983; T. R. Dafforn, J. Rajendra, D. J. Halsall, L. C. Serpell, A. Rodger, Biophys. J., 2004, 86, 404-410.

9. S. Fleming, P. W. J. M. Frederix, I. Ramos-Sasselli, N. Hunt, R. V. Ulijn, T. Tuttle, Langmuir, 2013, 29, 9510-9515. 